\title{
Formulações do conceito de elaboração psíquica no pensamento freudiano: apontamentos para um debate
}

\author{
Thiago Abrantes* (1) \\ Nelson Coelho $\mathbb{0}$
}

Universidade de São Paulo, Instituto de Psicologia, São Paulo, SP, Brasil

\begin{abstract}
Resumo: Discutiremos sobre o desenvolvimento da clínica freudiana e os impasses que surgiram no percurso de Freud que levaram a diferentes formulações do que, aparentemente, seria um conceito único de elaboração psíquica. Nosso objetivo é situar as condições históricas, teóricas e técnicas que possibilitaram a emergência das diferentes formulações da elaboração psíquica no desenvolvimento da clínica freudiana, investigando seus desdobramentos e suas variações. A primeira formulação da elaboração psíquica, a elaboração associativa, relaciona-se a um processo intrapsíquico, definido como a capacidade do psiquismo para ligar afetos e representações. Já a segunda, a perlaboração, relaciona-se com a superação de resistências, em um processo transferencial e interpsíquico, uma vez que é pelas intervenções do analista que a perlaboração encontra chances de ocorrer como potencialidade. Por fim, apontaremos que a segunda formulação acarreta a primeira, pois é pela superação das resistências que a associação de uma representação ocorre.
\end{abstract}

Palavras-chave: elaboração psíquica, Freud, Roussillon, resistência, perlaboração.

\section{Introdução}

Por que discutir elaboração psíquica? Acreditamos que ela está envolvida na ressignificação de experiências, naquilo que podemos chamar de convicção (Ferenczi, 1912/2011), fruto do trabalho analítico, visto em uma perspectiva de atenuação do sofrimento psíquico.

Nosso intuito neste texto é evidenciar que o conceito de elaboração é relevante para todo aquele que se dedica à prática clínica da psicanálise. Além do seu valor prático, podemos reconhecer seu valor histórico, dado que este pode servir como ponto de articulação do desenvolvimento da clínica freudiana, uma vez que foi por meio de seus desdobramentos que a técnica, gradualmente, passou por alterações.

Demonstraremos a maneira que as diferentes formulações da elaboração psíquica, quando relacionada com os conceitos de repetição, resistência e transferência, tece uma rede conceitual que fundamenta o trabalho psicanalítico e seus possíveis efeitos.

\section{A elaboração associativa, Verarbeitung ${ }^{1}$}

Ao acompanharmos o percurso clínico-teórico de Freud, é interessante notar um entrelaçamento entre a teoria e os desafios provenientes da prática clínica. Quando deparamos com seus escritos iniciais, é notável a percepção de uma grande e instigante oferta: a ressignificação de

\footnotetext{
* Endereço para correspondência: thiabrantes@gmail.com

1 Para discutir a tradução do termo, ver Hanns (1996, pp. 205-208).
}

experiências traumáticas que levariam a uma amenização total do sofrimento psíquico.

O ponto de partida para problematizar a questão aqui presente é a "Comunicação preliminar", texto escrito por Breuer e Freud (1893/2006a), no qual estes autores expõem suas descobertas a partir da condução clínica de experiências catárticas. Há, neste texto, a primeira formulação da elaboração psíquica na obra freudiana: a elaboração associativa. Ela é apresentada como o trabalho que o aparelho psíquico necessita realizar com o intuito de integrar as excitações que chegam até ele, estabelecendo entre elas elos associativos. $\mathrm{O}$ acúmulo de excitações não integradas no psiquismo seria o responsável pelo surgimento do sofrimento psíquico.

Gostaríamos de frisar que a elaboração associativa ocorre por meio de um trabalho fundamentalmente intrapsíquico e está relacionada, no desenvolvimento da obra freudiana, com a função de transmitir e ligar a energia oriunda da pulsão. É um trabalho intrapsíquico de remoção do excesso de investimentos. Seu impedimento seria uma das causas que provocariam a neurose e a ab-reação teria por meta destravá-la, ao promover a religação do afeto penoso com a representação original.

Em 1893, a elaboração associativa é encarada como um processo inerentemente associativo do psiquismo, que foi impedido de acontecer devido ao trauma. Nas discussões apresentadas por Breuer e Freud, há uma ênfase na importância de superar o conteúdo psíquico patogênico estratificado "camada por camada". Com isso, podemos entender que a atividade terapêutica 
era concebida como forma de desentravar o processo de elaboração, que até então estava impedido de acontecer.

Por isso, a recordação, sob hipnose, seria efetiva, uma vez que destravaria não só a lembrança de um evento traumático, mas também promoveria a ligação de sentido que faltava, conectando um afeto com sua representação correspondente. A ideia de assimilação, aqui, é quase instantânea ${ }^{2}$, porém não conseguia explicar a origem do sofrimento e tampouco o ressurgimento e deslocamento dos sintomas.

Nesse contexto, a maneira com que experiências traumáticas são ressignificadas acontece pela admissão afetiva de representações inconscientes relacionadas a essas experiências. A admissão está articulada com uma correção representacional, sendo que esta nova ligação é o resultado da atividade da elaboração associativa. Na ressignificação, está em jogo justamente o papel da interpretação como principal recurso técnico, isto para que ocorresse uma reação em cadeia: uma representação inconsciente era descoberta e prontamente revelada por Freud, a defesa caia, a elaboração associativa voltava a funcionar e a admissão afetiva acontecia.

Pontuamos que neste momento não havia ainda nenhuma discussão de Freud a respeito da relação terapêutica, e foi a partir das indagações e reflexões sobre este aspecto que ele constitui outra concepção de processo clínico na qual os conceitos de resistência e de transferência ganharam destaque particular tanto na teoria quanto na técnica freudiana. Tais fatores foram fundamentais para o surgimento da outra formulação da elaboração psíquica, a perlaboração.

$\mathrm{O}$ conceito de resistência foi introduzido no pensamento freudiano em 1895, definido como uma força que impõe obstáculos para o tratamento alcançar representações inconscientes que foram defendidas pelo Eu. Como consequência de sua prática clínica, Freud teorizou sobre a resistência, e isso o fez abandonar a hipnose para conseguir realizar uma investigação etiológica dos sintomas. A associação livre apareceu, naquele momento, como o substituto técnico da hipnose.

Durante o estudo deste percurso clínico inicial de Freud, encontramos uma novidade relacionada não à função da elaboração associativa, mas na maneira de delimitar sua área de atuação: ela não conectaria apenas afetos e representações correspondentes. Quando não há condições de encadear o afeto com uma representação possível, devido ao excesso de excitação, a defesa retira a representação da consciência e a elaboração associativa liga esse afeto recém-liberado a outra representação,

2 Nos casos atendidos por Freud nos "Estudos sobre a histeria", Lucy sofria porque estava apaixonada pelo patrão e não reconhecia. Já Elisabeth deparou com o mesmo sentimento pelo cunhado logo após a morte da irmã. Sublinhamos que os casos de Lucy e Elisabeth trazem duas contribuições importantes na concepção freudiana de tratamento para propiciar a elaboração associativa, e não em sua definição: fazer que o sujeito integre em si o afeto desinvestido pela defesa e o papel fundamental da interpretação para que a defesa fosse transposta. resultando naquilo que Freud chamou de uma "falsa ligação", que contém certa relação com a primeira.

Isso acontece porque o aparelho psíquico necessita diminuir a excitação que chega até ele, seja com ligações correspondentes ou equivocadas. Freud, inicialmente, acreditava que seria o conjunto de afetos "falsamente" conectados a representações que era transferido para a figura do analista. Esta conexão equivocada era vista por Freud como mais um sintoma e, por isso, necessitava ser suplantado pela superação das resistências, restabelecendo assim a ligação compatível entre representação e afeto.

Inicialmente, Freud presumia que a transferência operaria de maneira semelhante, sendo mais uma maneira de manifestação da resistência. Por isto, ele buscava superar o entrave transferencial revelando diretamente ao sujeito o que acontecia na relação terapêutica. O problema que apontamos aqui não passou despercebido por Freud, induzindo-o a realizar importantes alterações em sua abordagem clínica. Importante dizer que o objetivo e a função da elaboração associativa não sofreram alterações na obra freudiana, mas a maneira de propiciá-la clinicamente, sim.

Proporcionar um espaço no qual essas dimensões fossem trabalhadas e a elaboração associativa encontrasse possibilidade de ocorrer foi tarefa do tratamento. Ao propor alterações clínicas em sua técnica, Freud deparou com as noções de conflito e de defesa psíquica, em conjunto com as manifestações da resistência e da transferência, as quais tornaram necessário introduzir a segunda formulação da elaboração psíquica em seu pensamento (Durcharbeitung ${ }^{3}$ ), a perlaboração, que ganhou um estatuto próprio e reconhecido como o principal fator de operação da técnica psicanalítica.

A partir da problemática levantada por Freud no Posfácio do caso Dora (Freud, 1905/2006, pp. 108-116), notamos que não seria muito eficiente o analista exclusivamente interpretar a transferência ou perceber e apontar ao analisando sua dimensão de resistência e repetição. Desse modo, produzir conhecimento em análise passou a exigir um trabalho psíquico conjunto, do analisando e do analista, pois há a necessidade de que o primeiro supere suas resistências envolvidas no processo de desvelamento das representações inconscientes e o segundo formule interpretações.

A partir dos impasses transferenciais que Freud enfrentou com Dora, uma consequência dupla incidiu e passou a ser reconhecida sobre a constituição de qualquer situação analítica: (1) o próprio espaço clínico, contrariamente ao que Freud até então acreditava, impõe dificuldades nas associações e recordações do sujeito, dessa maneira, a resistência não se manifestaria apenas inibindo o fluxo associativo; e (2) o analista precisa considerar as manifestações transferenciais em suas intervenções, para daí haver a superação das resistências.

3 Para a tradução do termo, ver Hanns (1996, pp. 198-202). 


\section{A perlaboração, Durcharbeitung}

Seguindo o desenvolvimento clínico do pensamento freudiano, notamos a necessidade da formulação de um conceito específico para abarcar as dificuldades do analisando em superar os entraves da resistência. Foi inserido nas adversidades presentes neste caminho que a segunda formulação da elaboração psíquica, a perlaboração, apareceu no pensamento freudiano em 1914, como um trabalho a ser realizado pelo sujeito. Isso porque a simples interpretação do que era sentido e expresso transferencialmente não era muito efetiva e soava, por vezes, muito dogmática.

A perlaboração se coloca como um meio pelo qual seria possível o sujeito lidar com os afetos aflitivos que aparecem devido à resistência. Esta tem por função abarcar as dificuldades do encontro afetivo que se dá entre analista/analisando ao se relacionar com o trabalho, e esforço que precisa ser realizado pelo último para vencer as resistências que surgem no tratamento analítico.

A partir dos artigos técnicos, especialmente "A dinâmica da transferência" (1912/2010) e "Recordar, repetir e elaborar" (Freud, 1914/2010), a transferência já tem seu lugar constituído na teoria da clínica psicanalítica, não seria mais uma resistência a ocorrer nas análises, mas sim uma repetição necessária ao trabalho a ser feito de acesso às fantasias infantis recalcadas e ao complexo de Édipo. A transferência, a partir de 1912, passou a ser encarada como um processo constitutivo do tratamento psicanalítico, mediante o qual os desejos do sujeito são repetidos no âmbito da relação analítica remetidos à figura do analista.

O trabalho analítico seria caracterizado por um embate entre a atividade consciente e a vida pulsional do analisando, inconsciente. Tal confronto permearia a relação afetiva estabelecida entre analista/analisando. Assim, trabalhar com os impulsos afetivos em análise significaria prestar contas à resistência, é por isso que o manejo dos fenômenos transferenciais ofereceria as maiores dificuldades ao tratamento, pois eles "nos prestam o inestimável serviço de tornar atuais e manifestos os impulsos amorosos ocultos e esquecidos dos pacientes" (Freud, 1912/2010, p. 146).

Devido a isso, Freud enunciou que esses impulsos necessitam ser submetidos à atividade intelectual do sujeito para assim serem reconhecidos. Freud postulou aqui as direções que o trabalho analítico toma sob transferência. Seria um trabalho por e pelo afeto, mas que é atravessado em seu eixo pela resistência. Portanto havia a necessidade da formulação de um conceito que intermediasse esses dois polos.

É a esse contexto que o conceito de perlaboração se endereça, e o artigo "Recordar, repetir e elaborar" (1914) é uma tentativa de resolução desses impasses. Freud (1914) sugeriu que, na transferência, ocorre a evocação de certas passagens da vida real do sujeito e, na neurose de transferência, a substituição da neurose cotidiana.
Assim, o analista tem que utilizar a posição que lhe foi concedida pela transferência para reconduzir o analisando do repetir ao recordar.

$\mathrm{Na}$ relação transferencial, surgiriam as reações de repetição expressas pelo sujeito; o analista, ao percebê-las, traria ao analisando uma interpretação que, consequentemente, despertaria recordações. Porém essas últimas serão evocadas pelo sujeito apenas se houver a superação das resistências. $O$ trabalho da perlaboração permite ao analisando integrar e compreender uma interpretação e, consequentemente, superar as resistências que ela desperta. Isso não seria de fácil custo, tanto do lado do analista quanto do analisando:

nomear a resistência não pode conduzir à sua imediata cessação. É preciso dar tempo ao paciente para que ele se enfronhe na resistência agora conhecida, para que a elabore, para que a supere, prosseguindo o trabalho apesar dela, conforme a regra fundamental da análise. (Freud, 1914/2010, pp. 207-208)

É essa a passagem que denota a importância da segunda formulação da elaboração psíquica, a perlaboração, na obra freudiana. Porém, conforme exposto, não basta que o analista comunique ao sujeito algo que ele tenha descoberto e interpretado para que uma mudança interna ocorra no analisando, é necessário tempo. O tempo de gestação, inerente ao processo de perlaboração, para que o sujeito construa um saber de si mesmo a partir de sua própria experiência afetiva vivenciada em análise. A perlaboração aparece aqui como uma advertência a analistas iniciantes decepcionados com sua prática clínica, devido à demora e à dificuldade nos tratamentos. Fica claro como apenas exibir a resistência ao sujeito não seria o objetivo último de uma análise e, se for encarado como tal, ela se fortaleceria ainda mais e o tratamento não teria progresso. A atividade de perlaboração seria um difícil e penoso caminho de progressão no emaranhado de resistências. Seguindo Roussillon (2008), a perlaboração é um fator crucial da técnica psicanalítica, o que fundamenta sua prática clínica. Isso porque ela evita que a psicanálise seja mais uma terapêutica baseada na sugestão.

A perlaboração é o que possibilita ao sujeito a superação das resistências, sendo o elemento que fornece as condições para que ele construa um saber sobre si próprio, o que acontece de forma vagarosa. Freud (1914/2010) chegou a comparar, em âmbito teórico, a perlaboração com ab-reação das cargas de afetos retidos pelo recalque, $o$ que denota em que contexto ela ocorre, pois é um trabalho que se dispõe a lidar com a problemática imposta pela transferência-contratransferência. Ele busca restituir ao domínio psíquico do sujeito aquilo que é expresso na transferência, uma espécie de tempo necessário para que o sujeito a realize. Ela é um meio pelo qual seria possível remeter à recordação as repetições em análise dotadas de grandes cotas de afeto, configurando-se como um trabalho 
de superação das resistências oriundas do recalcado. Esse trabalho estabelece representações para integrar as excitações do psiquismo devido à dinâmica conflituosa oriunda do afeto. Apontamos que ela está relacionada ao esforço envolvido em superar as resistências para daí haver uma admissão afetiva, por meio do encadeamento associativo do que é sentido pelo sujeito.

Roussillon (2008) argumenta que, em 1914, a resistência aparecia oriunda do pré-consciente, isto é, do Eu pré-consciente, sendo essa a única modalidade de resistência evocada por Freud até então. O que está em cena no trabalho da perlaboração neste momento é tornar viável o retorno do recalcado mediante associações a respeito das formações pré-conscientes. Portanto, em 1914, Freud formalizou a perlaboração em estreita relação com apenas uma modalidade de resistência.

A perlaboração propiciaria caminhos para que o sujeito entre em contato com os conteúdos recalcados mediante sua atividade associativa. Dessa maneira, o trabalho do psicanalista se relaciona com

sua capacidade de "adivinhar", a partir das associações do paciente, quais representações inconscientes organizam as cadeias associativas, de reconstruir quais cenas históricas se escondem atrás delas e, depois, de comunicar ao analisando as que estão ativadas na e pela transferência. (Roussillon, 2008, p. 858)

Nesse sentido, no âmbito dos artigos técnicos freudianos, o que estaria em jogo no processo da perlaboração seria tornar possível o retorno de conteúdos recalcados por meio das associações do analisando oriundas dos encadeamentos pré-conscientes. A transferência ativaria aspectos referentes à dinâmica dos afetos e seria a partir do acesso do sujeito no processo de admissão desses afetos que as resistências apareceriam.

Contudo Freud (1920/2010, 1923/2010) notou, a partir dos impasses que enfrentou em sua clínica no caso do Homem dos Lobos ${ }^{4}$, que alguns conteúdos inconscientes não foram inicialmente representados e depois recalcados. Desse modo, tais conteúdos jamais ascenderam à consciência, eles não tiveram nenhum tipo de simbolização e representação. Supomos, então, que o primeiro modelo da perlaboração de 1914 não daria mais conta aqui, uma vez que esta foi concebida para lidar com a resistência do recalcado, a qual partia do princípio de

4 Freud relatou a grande dificuldade em conduzir tal tratamento, assim como a impossibilidade de encontrar uma intervenção efetiva: "O paciente de que me ocupo permaneceu muito tempo entrincheirado, inatacável, detrás de uma postura de dócil indiferença. Ele escutava, entendia e não permitia que nada se aproximasse" (Freud, 1918[1914]/2010, p. 18, grifos nossos). Ao deparar com tamanha dificuldade, "Determinei ... que o tratamento tinha que findar em um determinado prazo, não importando até onde tivesse chegado; prazo este que eu estava determinado a cumprir" (Freud, 1918[1914]/2010, p. 19, grifos nossos). Acreditamos que foi por todos esses fatores que Freud realizou nessa análise o que foi chamado de interferência ativa, determinar uma data para o fim do tratamento, buscando algum meio de fazer esta análise avançar. que os conteúdos psíquicos haviam sido representados e, posteriormente, recalcados.

No texto "Inibição, sintoma e angústia", Freud (1926/2014), após já ter introduzido a segunda tópica do aparelho psíquico, diferenciou a resistência em três categorias: (1) resistências do Eu (resistência do recalcado); (2) do Id (compulsão à repetição); e (3) do Supereu (sentimento inconsciente de culpa).

Tendo como ponto de partida essas três categorias, Roussillon (2008) apresenta três diferentes tipos de situações transferenciais nas quais a perlaboração ocorre, porém muda de natureza à medida que um ou outro tipo de resistência estaria presente. Consequentemente, o enquadre transferencial é alterado, sempre exigindo maior atenção à intersubjetividade da situação analítica, discutida em torno da implicação e do comprometimento do analista ao lado do manejo com a transferência negativa.

$\mathrm{O}$ autor francês defende que seria mediante sua percepção da relação transferencial que um analista pode notar a possibilidade de uma ou mais experiências não terem sido integradas no Eu, isto é, sem representação nos registros consciente/pré-consciente. Para entendermos melhor a questão da possibilidade/impossibilidade de integrar uma experiência no psiquismo, Roussillon (2007) acredita que o funcionamento psíquico sempre desempenha uma função em relação ao limite:

Não há funcionamento psíquico que não encontre o limite e deva tentar tratá-lo de uma maneira ou de outra. O limite representa uma função básica do funcionamento psíquico, na medida em que contribui para organizar os processos reguladores mais importantes da economia psíquica e da pulsionalidade que a percorre. (p. 259)

Aqui, a atividade associativa do Eu não consegue sobreviver sem a existência de processos que o informem a respeito dos seus limites. Tal processo estaria evidente em qualquer movimento pulsional, na medida em que este sempre deve ser acompanhado de um contramovimento, limite que o interdite de ocupar todos os lugares possíveis. Seria a aceitação da coexistência dos contrários que garantiria o limite entre cada ligação libidinal. Sendo que este limite desempenha sua função quando a identidade de percepção eu/outro fracassa, assim a principal questão torna-se como o

5 É importante salientar aqui que essa proposição de Roussillon parte da ideia freudiana de que o aparelho psíquico precisa manter um nível de constância em relação à excitação que chega até ele. Assim, partindo das teorizações freudianas, sempre que uma experiência, seja ela psíquica ou relacional, aumentava muito o nível de excitação do psiquismo, a representação do que foi vivido era recalcada ao inconsciente (Abrantes, 2016). Contudo Freud notou que, dependendo da intensidade e situação que um sujeito experiencia algo, não há condições do Eu associar e representar: "A partir de 1917, 1918, 1920, Freud fará evoluir esse modelo. Considerará que certo número de coisas nunca foram conscientes. Então, não é possível tomar consciência, retomar consciência de algo que nunca foi recalcado porque nunca foi consciente" (Roussillon, 2013, p. 110). 
limite perpassa o Eu (aquilo que é possível ao psiquismo integrar) e o não Eu. Seria em um momento como este que o funcionamento psíquico recorre às variantes da função-limite para enfrentar as consequências e ameaças de um funcionamento totalitário e unitário da psique, resultando na não diferenciação Eu/Outro.

Conforme Freud apontou em 1926, a primeira categoria de resistência é a do Eu pré-consciente. A orientação clínica freudiana continua a mesma apresentada em 1914, viabilizar o retorno do inconsciente recalcado por meio das associações feitas sobre as formações do pré-consciente. Para tanto, o enquadre clínico conta com a associação livre do sujeito e com a neutralidade e a atenção flutuante do analista. O que está em evidência no processo de perlaboração, então, é possibilitar a volta do inconsciente recalcado a partir dos encadeamentos pré-conscientes derivados dele.

A partir do que Freud apresentou em 1926, a resistência do Id diz respeito às situações traumáticas, nas quais as possíveis representações foram contrainvestidas antes de qualquer possibilidade de associação. A sobrecarga na sensação de desprazer, pelo terror ou pela angústia envolvidos, impede o trabalho da elaboração associativa. Aqui, antes de alguma vivência e representação possíveis, ocorre a atuação da defesa primária. Importante lembrar que, na fronteira entre o Id e o Eu, encontra-se a combinação de percepções múltiplas (dentro/fora), várias sensações, moções pulsionais conflituosas. É o aporte na combinação de uma parte de si mesmo na experiência subjetiva em conjunto com a parcela e as respostas do outro, o que exige um constante trabalho de transformação e descondensação (trabalho metaforizado aqui em torno da elaboração associativa), em um constante ir e vir entre interno e externo, em um jogo de transferências e transposições.

Por vezes, esse trabalho é impedido de ocorrer aqui estamos na alçada no recalque originário. Vale lembrar que este atrai em torno dele os recalques secundários, os quais são os relativos ao modelo da perlaboração apresentado por Freud em 1914, destaca Roussillon (2008). Vemos que a perlaboração da resistência do Id exige um trabalho de transformação para que conteúdos, até então nunca tornados conscientes, tornem-se passíveis de serem associados pelo $\mathrm{Eu}$.

Para tanto, de acordo com Roussillon (2008), é necessário o auxílio do analista no que ele chamou de descondensamento do conteúdo-alvo do recalque originário, o que se daria "fragmento por fragmento". O que evitaria o risco de cairmos em uma análise puramente representacional é a discussão em torno das manifestações transferenciais negativas ou situações nas quais ocorre o predomínio de um funcionamento masoquista, apático e/ou melancólico. Estaríamos diante das chamadas "situações-limite" da psicanálise (Roussillon, 2005).

O trabalho de perlaboração das resistências do Id ocorre pelo caminho que parte das manifestações, por vezes alucinatórias, de identificação transferencial até o reconhecimento, daquilo vivido na transferência, como representação psíquica. A ideia é que aquilo que se repete na transferência possa ser reconhecido como uma parte do passado, e não mais com seu poder de atualidade. O que exige a apropriação da experiência traumática, tornando-a consciente, isto é, passível de associação pelo sujeito. É necessário um trabalho de reconstrução, que coloca o analista em um lugar distante do modelo de 1914. Isso porque, primeiramente, tem que conter e metaforizar as situações traumáticas para, em um segundo momento, o sujeito ter condições de se apropriar delas e associá-las.

Há uma forte ênfase aqui em aspectos intersubjetivos, no uso da contratransferência como maneira de dar forma a sensações e percepções do sujeito ao lado do papel da construção, já que a representação construída é produto do trabalho analítico. Roussillon (2008) acredita que esse é um trabalho "lado a lado", de coconstrução. Mesmo a situação analítica sendo assimétrica, a ideia é que a dupla analítica se apoia um no outro e no trabalho do outro sobre sua própria parte, para assim conseguir acessar, viver e representar as primeiras relações objetais do sujeito.

Contudo uma questão importante se impõe: situações relativas à sedução e sugestão na e pela análise. A vertente da transferência negativa também impede a capacidade de pensar do próprio analista e, assim, precipita defesas que não passam despercebidas pelo sujeito. Quando se fala de um trabalho analítico construído a dois, nos quais aspectos intersubjetivos são fundamentais, uma questão importante seria quais são as condições de apropriação dadas e oferecidas ao sujeito. O sentimento inconsciente de culpa, pano de fundo das manifestações transferenciais negativas, pode causar uma identificação por sugestão, alienante, podendo aumentar ainda mais a expressão de sentimentos negativos em análise. Ter acesso e representar o conteúdo-alvo do recalque originário não seria suficiente em si, pois é fundamental saber, aponta Roussillon (2008), de quem veio e como foram criadas as condições para a apropriação subjetiva do que foi revelado pela análise. Isso para evitar o risco do sujeito ser seduzido ou submetido por e pela situação analítica. Estamos aqui no terreno da perlaboração das resistências do Supereu.

$\mathrm{Na}$ análise, também é necessário entender como ocorreu a influência dos objetos parentais do sujeito que moldaram o Eu, apoiando a formação do Supereu. A chamada sombra dos objetos parentais traveste-se na sombra do próprio Supereu. Assim como é fundamental a análise da resistência do Supereu do sujeito, seria de igual importância o analista entender a sombra que o acomete, seus ideais, suas teorias, sua maneira de trabalhar, que podem recair ou cobrir a análise. Está aí uma importante razão para a análise do analista.

Conforme Roussillon (2008) destaca, a ideia é que, durante o trabalho de coconstrução, essencial para as resistências do Id, o analista não ficaria imune 
em descobrir algo sobre si mesmo, principalmente de seus ideais. Não levar isso em conta pode capsular um ou mais pontos da contratransferência, aumentado a submissão ou fomentando uma revolta do sujeito diante de um Supereu ideal do $\mathrm{Eu}$, o que produz uma alienação em análise. Admitir o que pode existir do par sugestãosedução na análise é imprescindível para lidar com a resistência do Supereu, o que obriga o analista a lidar com seu narcisismo. Após conter e sustentar os ataques negativos do sujeito, esse atestado de sobrevivência, seria possível ao sujeito uma diferenciação entre $\mathrm{Eu}$ e não $\mathrm{Eu}$, posicionamento do analista importante para não reeditar em análise sujeições traumáticas infantis.

Nos casos considerados mais graves, nos quais as resistências do Id e do Supereu estariam em maior evidência, de acordo com Green (1974), haveria um funcionamento psíquico que ameaça a autoconservação do sujeito, suas lógicas de vida, sendo que ele tende a substituí-las por lógicas de sobrevivência. Diante de tais quadros, vale frisar que os dispositivos-padrão analíticos podem se tornar uma grande ameaça para o registro econômico, associativo, do psiquismo. Conforme Roussillon (2008) aponta, o que estaria em jogo nesse contexto seria em quais momentos o analista, a partir de suas percepções do que o outro provoca nele, destacaria fragmentos das diferentes instâncias psíquicas (Eu, Id e Supereu), sendo que cada instância tem uma forma de funcionamento própria e, portanto, diferentes categorias de resistência, e, como vimos, envolvem um tipo de perlaboração diferente.

A noção de situação analisante, proposta por Donnet (2005), pode ser uma maneira de sustentar os diferentes enquadres clínicos que um analista precisa fazer para que a perlaboração das diversas categorias da resistência ocorra. Figueiredo (2011) argumenta que tal noção ajuda a tornar mais clarividente a dimensão dinâmica do dispositivo clínico psicanalítico, assim como de todas as suas variantes, na medida em que estas estariam envolvidas em um dinamismo inerente à prática clínica da psicanálise. Nesta perspectiva, as mudanças na teoria da técnica, quando pesquisadas e apresentadas em sua genealogia, potencializam-se. Como resultado, podemos ter a concepção de fazer da situação analisante uma entidade viva e em contínuo processo de transformações e retransformações ${ }^{6}$.

A este trabalho de instalação, monitoramento e sustentação da situação analisante cabe o conceito de 'manejo' em sentido amplo. Também as intervenções estritamente interpretativas do analista precisam estar subordinadas às estratégias e táticas de manejo, pois é na própria operatividade da situação analisante que reside o essencial da clínica analítica. (Figueiredo, 2011, p. 193)

6 Aqui estão presentes os problemas relacionados ao enquadre e à posição do analista, remetendo-nos não apenas a uma técnica, mas à ética da psicanálise (Figueiredo, 2008).
Acreditamos que as diferentes nuances que a perlaboração pode assumir, dependendo da categoria de resistência envolvida em determinada situação ou momento específico, apontam para a necessidade do estabelecimento de uma relação intersubjetiva, ao passo que a eficácia do tratamento psicanalítico, defendida aqui em torno da perlaboração, depende de uma condição prévia: a constituição, o estabelecimento e a operatividade de uma situação analisante.

\section{Considerações finais}

Acreditamos que, quando uma experiência, seja ela de origem intrapsíquica ou relacional, introduz uma cota a mais de excitação no aparelho psíquico, este terá de ligá-la e associá-la de algum modo, vinculando-a a representações já existentes no psiquismo. Esta seria a dimensão da elaboração associativa, relacionada a um processo psíquico que pode dar origem a um sonho, um devaneio, um poema, uma obra de arte, um chiste, um ato falho. Aparentemente, a partir da obra freudiana, apenas quando isso não ocorre é que a neurose se faz presente. Quando tal trabalho não é possível, dependendo da intensidade e singularidade da experiência, o recalque incide, produzindo sintomas, rechaçando, para o inconsciente, representações relacionadas ao que foi experienciado. No momento em que, fundamentalmente fruto de um trabalho analítico, como defende Freud, a resistência a alguma representação inconsciente começa a ser superada, a possibilidade de admissão do sujeito daquilo que ele sentiu e viveu torna-se possível. Esta seria a dimensão da segunda formulação da elaboração psíquica, a perlaboração no pensamento freudiano, estritamente relacionada como fator essencial da técnica psicanalítica.

Conforme exposto, Freud estruturou um trabalho terapêutico construído em torno do afeto e das representações. Na primeira formulação do conceito de elaboração, feita por ele em 1893, pode ser vista a importância dada em relação à presença do afeto no tratamento, sendo que a elaboração associativa é o tempo necessário para que o sujeito reconheça e trabalhe com sua experiência afetiva, o que está muito distante de uma simples decifração de conteúdos aflitivos. Na segunda formulação, realizada em 1914, Freud afirmou que a perlaboração representa o trabalho analítico fundamental para desvendar conflitos e resistências. Estes dois trabalhos estão relacionados a contextos diferentes. Frisamos que a perlaboração é um facilitador para que a elaboração associativa ocorra. Isso porque a elaboração associativa se refere a um processo intrapsíquico e associativo, definida como uma tendência inerente ao psiquismo e que só é barrada quando há um aumento no nível de excitação. Já a perlaboração se relaciona com a superação das resistências, sendo um processo transferencial e intersubjetivo. Defendemos que a perlaboração está relacionada, especificamente, ao trabalho envolvido em superar as resistências para, a partir daí, haver a elaboração associativa do que é sentido pelo sujeito, resultando na admissão afetiva. 
Ao situar a perlaboração como premissa fundamental para a recordação e superação das resistências, Freud introduziu o conceito de que a repetição feita pelo paciente na análise é expressa como forma de resistência ligada a uma experiência afetiva. Ao atribuir maior importância à análise dos mecanismos de defesa, Freud foi levado a reconhecer a necessidade de um trabalho compatível com tais mecanismos, a perlaboração seria o expoente.

Este conceito, em suas duas formulações, fez que questionássemos os parâmetros norteadores da clínica. Concluímos que eles buscam promover um espaço para a expressão afetiva no tratamento. A partir das noções de tempo, paciência e convicção, o analista promove condições de existência para a presença da perlaboração, tirando-nos de um campo estritamente técnico e realocando-nos para o campo ético. É por meio do modo como o analista se afeta e se deixa afetar pelo outro que a perlaboração se torna possível. Nas reflexões feitas aqui, vimos a possibilidade de pensar sobre os modos de um analista alterar o enquadre de um caso, dependendo das diferentes dimensões do encontro transferencial e/ou do próprio diagnóstico. O campo teórico que fundamenta esse posicionamento do analista é o reconhecimento do papel da transferência e o da contratransferência, em conjunto com a forma que pode proporcionar que um sujeito perlabore suas resistências.

\section{Concept of psychic elaboration in Freudian thought: notes for a debate}

Abstract: This paper discusses the development of the Freudian clinic and the impasses in Freud's course that led to different formulations of what would apparently be a single concept of psychic elaboration. It seeks to situate the historical, theoretical, and technical conditions that enabled the emergence of different formulations of psychic elaboration during the development of the Freudian clinic, investigating its developments and variations. The first formulation of psychic elaboration, associative elaboration, is related to an intrapsychic process, defined as the psyche's ability to link affections and representations. The second, working-through, is related to overcoming resistance, in a transferential and interpsychic process, since it is through the analyst's interventions that working-through finds chances to occur as potentiality. Finally, the paper points out that the second formulation entails the first, since it is by overcoming resistances that the association of a representation occurs.

Keywords: psychic elaboration, Freud, Roussillon, resistance, working-through.

\section{Formulations du concept d'élaboration psychique dans la pensée freudienne : notes pour un débat}

Résumé : Cet article traite du développement de la clinique freudienne et des impasses du parcours de Freud qui ont conduit à différentes formulations de ce qui serait apparemment un concept unique d'élaboration psychique. L'objectif est de situer les conditions historiques, théoriques et techniques qui ont permis l'émergence de différentes formulations d'élaboration psychique au cours du développement de la clinique freudienne, en étudiant ses déroulements et ses variations. La première formulation de l'élaboration psychique, l'élaboration associative, est liée à un processus intrapsychique, défini comme la capacité du psychisme à relier les affections et les représentations. La seconde, la perlaboration, est liée au dépassement de la résistance, dans un processus transférentiel et interpsychique, puisque c'est à travers les interventions de l'analyste que la perlaboration trouve des chances de se produire comme potentialité. Enfin, l'article souligne que la seconde formulation entraine la première, car c'est en surmontant la résistance que l'association d'une représentation se produit.

Mots-clés : élaboration psychique, Freud, Roussillon, résistance, perlaboration.

\section{Formulaciones del concepto de elaboración psíquica en el pensamiento freudiano: notas para un debate}

Resumen: Discutiremos el desarrollo de la clínica freudiana y los callejones sin salida que surgieron en el camino de Freud y lo condujeron a diferentes formulaciones de lo que sería, aparentemente, un concepto único de elaboración psíquica. Nuestro objetivo es situar las condiciones históricas, teóricas y técnicas que hicieron posible el surgimiento de diferentes formulaciones de elaboración psíquica en el desarrollo de la clínica freudiana, investigando sus desarrollos y variaciones. La primera formulación de elaboración psíquica, la elaboración asociativa, está relacionada con un proceso intrapsíquico, definido como la capacidad de la psique para vincular afectos y representaciones. La segunda, la perlaboración, está relacionada con la superación de la resistencia, en un proceso transferencial e interpsíquico, ya que es a través de las intervenciones del analista que la perlaboración encuentra posibilidades de ocurrir como potencialidad. Finalmente, señalaremos que la segunda formulación produce la primera, porque al vencer la resistencia ocurre la asociación de una representación.

Palabras clave: elaboración psíquica, Freud, Roussillon, resistencia, perlaboración. 


\section{Referências}

Abrantes, T. (2016). As formulações da elaboração psíquica (Verarbeitung e Durcharbeitung) no pensamento freudiano: dos estudos sobre a histeria aos artigos técnicos (Dissertação de Mestrado). Universidade de São Paulo, São Paulo, SP.

Breuer, J., \& Freud, S. (2006a). Sobre o mecanismo psíquico dos fenômenos histéricos: Comunicação preliminar. In Obras psicológicas completas de Sigmund Freud (J. Salomão, Trad., Vol. II, pp. 39-53). Rio de Janeiro, RJ: Imago. (Trabalho original publicado em 1893)

Donnet, J. L. La situation analysante. Paris: PUF, 2005.

Ferenczi, S. (2011). Sintomas transitórios no decorrer de uma psicanálise. In Obras Completas: Psicanálise I (A. Cabral Trad., Vol. 1, 2a ${ }^{\circ}$ ed., pp. 213-224). São Paulo, SP: Martins Fontes. (Trabalho original publicado em 1912)

Figueiredo, L. C. (2008). Presença, implicação e Reserva. In L. C. Figueiredo \& N. Coelho Jr, Ética e técnica em psicanálise ( 2 a ed.). São Paulo, SP: Escuta.

Figueiredo, L. C. (2011). A questão dos limites e a situação analisante na clínica contemporânea. In C. A. Garcia \& M. R. Cardoso (Orgs.), Limites da clínica: clínica dos limites (pp. 185-207). Rio de Janeiro, RJ: Cia de Freud.

Freud, S. (2006). Fragmento da análise de um caso de histeria. In Obras psicológicas completas de Sigmund Freud (J. Salomão, Trad., Vol. VII, pp. 15-116). Rio de Janeiro, RJ: Imago. (Trabalho original publicado em 1905[1901])

Freud, S. (2010). A dinâmica da transferência. In Sigmund Freud: Obras completas (P. César de Souza, Trad., Vol. 10, pp. 133-146). São Paulo, SP: Companhia das Letras. (Trabalho original publicado em 1912)

Freud, S. (2010). História de uma neurose infantil. In Sigmund Freud: Obras completas (P. César de Souza, Trad., Vol. 14, pp. 13-160). São Paulo, SP: Companhia das Letras. (Trabalho original publicado em 1918[1914])
Freud, S. (2010). Recordar, repetir e elaborar. In Sigmund Freud: Obras completas (P. César de Souza, Trad., Vol. 10, pp. 193-209). São Paulo, SP: Companhia das Letras. (Trabalho original publicado em 1914)

Freud, S. (2010). Além do princípio do prazer. In Sigmund Freud: Obras completas (P. César de Souza, Trad., Vol. 14, pp. 161-239). São Paulo, SP: Companhia das Letras. (Trabalho original publicado em 1920)

Freud, S. (2010). O Eu e o Id. In Sigmund Freud: Obras completas (P. César de Souza, Trad., Vol. 16, pp. 13-74). São Paulo, SP: Companhia das Letras. (Trabalho original publicado em 1923)

Freud, S. (2014). Inibição, sintoma e angústia. In Sigmund Freud: Obras completas (P. César de Souza, Trad., Vol. 17, pp. 13-123). São Paulo, SP: Companhia das Letras. (Trabalho original publicado em 1926)

Green, A. (1974). L'analyste, la symbolisation et l'absence. Nouvelle Revue de Psychanalyse, 10, 2225-2252.

Hanns, L. A. (1996). Dicionário comentado do alemão de Freud. Rio de Janeiro, RJ: Imago.

Roussillon, R. (2005). Paradoxos e situações limite da psicanálise. São Leopoldo, RS: Unisinos.

Roussillon, R. (2007). A função limite da psique e sua representância. Revista de Psicanálise da SPPA, (2), 257-273.

Roussillon, R. (2008). Pelaboration et ses modèles. Revue Française de Psychanalyse, (3), 855-867.

Roussillon, R. (2013). Teoria da simbolização: a simbolização primária. In L. C. Figueiredo, B. B. Savietto, \& O. Souza (Orgs.), Elasticidade e limite na clínica contemporânea (pp. 107-122). São Paulo, SP: Escuta.

Recebido: $24 / 04 / 2020$

Aprovado: 30/07/2021 